\title{
Some virtues, values and purposes in the challenges faced by physicians
}

\author{
José Ricardo de C. M. Ayres
}

\section{A HUNDRED CHALLENGES}

was very happy and honored to be invited
by the Revista de Medicina to participate in commemorating the significant date of its centenary by writing an article. The hundredth anniversary of a journal that is completely directed by undergraduate students is an extraordinary event, and even more so, given the quality that has been maintained since its first issues. However, my initial happiness soon gave way to worries: I had been asked to discuss a hundred challenges faced by physicians!

It was not that it would be difficult to find a hundred challenges faced in practicing this profession, but very much the contrary! If I cast an eye back over my own experience as a physician, including the choice of career, university entrance examinations, studies and experiences over the six years of training, residency, professional practice and the roles that physicians are entrusted with by society, within family life and public life in general, I would be able to identify not one hundred but hundreds of challenges.

To choose and discuss one hundred of these challenges involved two difficulties for me. On the one hand, I certainly did not feel that I was good enough as a wordsmith to retain the readers' attention for such a lengthy piece (would they be able to reach this far?). On the other hand, would the path outlined be excessively singular? Would it be possible for my experience to reflect that of others? Isn't one of the innumerable and fascinating characteristics of medicine the fact that it consists of a very wide and diverse field of activity that is always in a state of rapid and intense transformation?

Conscious of the difficulty, I thought it would be prudent not to venture down this path... prudent. Prudence: one of the virtues that, in ancient times, was considered to be fundamental for dealing with the vicissitudes of practical life. Eureka! Better than enumerating challenges: why not speak of the virtues needed for facing them?! Perhaps, through this path, it would be possible to get round the two difficulties laid out above: I would not tire readers out with my poor talent for discussing so many challenges in an attractive manner; while at the same time, I would avoid the risk of generalizing challenging experiences that might not be exactly the ones that other people embarking on a medical career will have to face along their own paths.

By definition, virtues should be universal in nature. However, as the eternal master Aristotle taught us, these virtues will only be demonstrated in the concrete situations to which they apply ${ }^{1}$. For this reason, to find the right distance between a very abstract universal plane and very particular practical situations, I will put forward some more modest mathematics here: instead of one hundred challenges, I propose to discuss four virtues, five values and three purposes that seem to me to be precious for

Professor of the Department of Preventive Medicine - Medical School of the University of São Paulo.

Mailing Address: Av. Dr. Arnaldo, 455 - $2^{\circ}$ andar. São Paulo, SP, Brazil. CEP: 01246-903. Email: jrcayres@usp.br 
facing the challenges of being a physician. I feel that, in this manner, I will not be diverging from the spirit of the proposed reflections and perhaps will be making a better contribution, within my limits, so that we might be better equipped to distinguish the day-to-day challenges that we encounter over the course of our professional lives, and maybe even to face them wisely.

\section{FOUR VIRTUES}

Although finding a definition for virtue may be a difficult task, given the different meanings that have been assigned to this term (and the concept) over the course of history, it will be enough for me if we take it here to simply (simply?!) mean a propensity to want to do good and the habit of doing $\mathrm{SO}^{2}$. In other words, independent of the nuances that this might have, in terms of understanding both how this is managed, implemented and implied in dayto-day life and what the fundamental virtues are (if these can really be defined), it is important here to retain the idea of virtue as this movement of our thoughts, feelings and deeds that is directed fundamentally towards what we can considered to be appropriate for achieving a good life. In other words, it is a movement towards what we can consider to be life in its fullest and best-shared translation and, by extension, also towards good medicine.

Ever since Plato defined four fundamental virtues, which St. Ambrose later on called the cardinal virtues (prudence, courage, temperance and justice), and Aristotle made discussion of ethics a fundamental part of philosophy, ${ }^{1}$ we (their cultural heirs in the West) have unceasingly asked what a good life consists of and how we can attain it; or rather, how we can know whether we are or are not heading towards it. We physicians, through the very nature of our day-to-day profession, whatever our branch of medicine, cannot in any way skirt round these questions. In terms of challenges in this regard, it will certainly not only be scientific and technical tasks that we are referring to, but also ethical and moral issues ${ }^{3}$. We all know, through experience, that to say that a physician is scientifically educated and/or technically skilled does not automatically mean that this professional is virtuous. So, what would it take for us to become virtuous professionals?

Sincerely, I would not be able to swear that there are four virtues from which the full ethical dimensions of human life would unfold. Or that there are three of them, or seven, or a varying number according to how changes occur within the practical situations that, over the course of the history of humanity or of the lives of each of us, keep on practically challenging us and making us think what best to do and what might be the wisest decision in each situation, and how to act in this regard. For example, chastity was once considered to be a virtue for women and chivalry a virtue for men. Today, there is certainly no longer any unanimity regarding the importance of either of these, in themselves, for achieving a good life, and even less so regarding the gender stereotype that accompanies them. However, given that I was not commissioned to write a specialist article on ethics, but only a reflective essay, I will venture to discuss virtues that seem to me to be fundamental for good medical practice, but not without the due tributes to intellectual responsibility. These virtues certainly owe much, quantitatively and qualitatively, to the philosophical exercises of the great masters on this subject, like Plato, Aristotle, Espinosa, Kant and Nietzsche, among others. Nonetheless, to lean on the authority of these thinkers to legitimate what I will present here would be just as unfair as to claim any originality in relation to everything that they developed.

With this said, I will select four virtues as supporting points for seeking a good life and consequently, good medicine. These are interrelated virtues, and I would even say that they are interdependent, because one cannot be achieved as such without concomitant mediation from another.

\section{Courage}

Courage can be understood here in the general sense of an attitude or inclination of openness towards facing difficult situations. It is an attitude of fighting for a cause when, even without a priori guarantees of success, we sense that the cause is worth fighting for. Such causes transcend our search for immediate pleasure, wellbeing and comfort. On the contrary, they may even occasionally mean foregoing these desires, as did Socrates, in marginal situations that we judge to be essential or unavoidable in reaching the values of a good life. Courage consists 
of facing up to the challenges that give meaning to our existence.

\section{Humility}

Courage would be blind or, worse, violent or suicidal if it were not accompanied by an attitude of recognition of our situation of limitation, incompleteness and dependence on other people in a variety of day-to-day situations. This is humility, and it has nothing to do with authentic or simulated self-deprecation, or with sentiments of diminishing the importance of oneself or of situations. On the contrary, humility implies an enduring awareness of the importance, when doing something that involves other people, of not doing it to the detriment of these others or of oneself, so that the value of the action will be effectively understood and attained. One does not need to be Catholic to see, for example in the story of St. Francis of Assisi, that the virtue of humility does not conflict with courageous affirmation of a position. On the contrary, the combination of humility and courage was fundamental in his case, for the values that guided his religious quest to be developed and achieved.

\section{Strength}

To be strong is to use our physical, mental and moral resources towards achieving our values. This is a form of perseverance, vigor or intensity that preserves our power to think, feel and act towards a good life, even in unfavorable situations. We can perhaps understand this virtue as the support that adds resistance to courage and supplies energy for facing up to challenges, even when the action is limited. Is it not this virtue that, for example, lies behind histories of endurance of long years of prison of people like Nelson Mandela?

\section{Serenity}

Humility is to courage in the same way that serenity is to strength. Strength without serenity is tension: energy that is consumed without direction. We need to be serene so that we have the wisdom to identify the time and means for pursuing our values (with courage and humility). We need serenity so that we do not let our hopes become reduced to resignation and desistance. This is perhaps the virtue that comes to the forefront in the conduct of people who we usually call survivors of various human failings: war, hate, prejudice, accidents, exclusion and abandonment. Without serenity, courage, humility and strength would not have had the power to lead them to victory in their struggles, which in turn allowed us to know about them and learn from them.

\section{FIVE VALUES}

It should have become more or less clear, despite the very summarized nature of the exposition above, that virtues are always placed in relation to a certain horizon that provides us with a measurement to judge whether it is worthwhile acting or not, in one direction or another, with careful attention to oneself and to the other person, thereby constituting something of value. Defining value is not exactly easy, but in simple terms we can say that it refers to a condition in which a subject or group of subjects holds in some esteem, i.e. seeks to attain or preserve ${ }^{2}$. As we saw above, this esteem will always be evaluated through reference to some purpose. We can speak of value from the points of view of mathematics, music, economics, culture, value of use, exchange value, etc. Here, we are referring to value from the perspective of ethics and therefore the reference is a good life, and our specific field of action is medicine. In this regard, I will conduct an exercise to select at least five values among those that I judge should be directing our virtues for good medical practice.

\section{Happiness}

Depending on how we approach happiness, it can be considered to range from a fleeting condition of satisfying an inclination to a state of consciousness that in ancient times was called eudaimonia, or beatitude (or nirvana, in the Hindu sense). This characterizes not so much satisfaction in itself but, rather, a positive state of mind in relation to different inclinations and the ways in which they can be satisfied ${ }^{4}$. In our case, I am taking it to be a value in the particular sense of placing us at the level of professional tasks, such that through prevention and treatment of diseases or subsequent rehabilitation, 
we aspire to go beyond satisfaction. We need to be ready to understand and manage people's health needs and their demands for care as being socially and individually rooted in aspirations towards a more profound experience of wellbeing, even if living with health problems cannot be completely minimized, and especially under these conditions. After all, concern for this horizon of wellbeing, or what some have called a "project of happiness", is what allows us to optimize the good and minimize the harm that we might do to people and communities that we care for, through developing, applying and teaching the sciences and techniques that we use in our profession ${ }^{5}$.

\section{Justice}

As we saw above in discussing humility, our relationship with other people is fundamental for virtuous implementation of our actions towards a good life. Being fair is also a value in medicine. We know that we are unequal and that we are singular beings, but this inequality cannot create disadvantages for some in relation to others with regard to achieving a good life. For this reason, equity is as precious as good healthcare practices, such that it has become indissociable from universality and comprehensiveness as the doctrinal principles of SUS, the Brazilian healthcare system. The Portuguese social scientist and philosopher Boaventura de Souza Santos drew up the inspired maxim "we have the right to be equal whenever differences make us inferior; we have the right to be different whenever equality takes away our

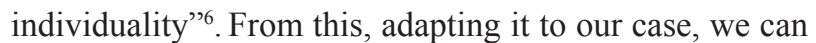
summarize the value of justice by stating that care should be practiced equally for all whenever inequality gives rise to disrespect or excludes someone or some people, but that it should be practiced in a differentiated manner whenever equality of care conceals or neglects each individual's or communities' specific needs. For this reason, dialogue between health and rights is important at all levels: from individual consultations to policy making.

\section{Truth}

Even if I run the risk of being repetitive, it has to be remembered that here too, we are in a place where it is difficult to find suitable definitions. For our purposes, in overall terms, we will take the truth to be judgments expressed with regard to the reality that can rationally be sustained and be validated through communication ${ }^{7}$. In the case of medicine, which is a practice that implies highvalue decision-making with regard to people's lives, both in the physical sense and in the sense of moral practice, construction and sharing of judgments that are solidly accepted as true is fundamental. For this reason, our technical and scientific expertise is extremely important, and this puts us under an obligation towards lifelong study and technical improvement. However, it is equally important to also remember the truths that do not relate to a strictly technical-scientific level, like those that we are dealing with here. Therefore, it is also important to actively seek humanistic training for students and practitioners of medicine. Moreover, and more fundamentally, there is a need to be very attentive to the truth that people and communities accumulate and bring into healthcare practices within their day-to-day knowledge. They possess the deepest knowledge of the realities that only they experience, which forms their practical wisdom. In the same way, we accumulate practical wisdom through our professional lives that is not taught to us through classes or in books.

\section{Compassion}

The notion of compassion is a close neighbor of sympathy and empathy. The notion of empathy has been much more frequently discussed in the medical literature. In the manner in which I will highlight compassion here as a value, it refers to the movement towards participating in the pathos experienced by the other person ${ }^{8}$. In other words, those whose professional practice puts them in a position to help people to find their wellbeing cannot be indifferent to the other person's suffering and happiness. However, compassion can be differentiated from pity, commiseration or any other sentiment of sadness or disbelief on another person's resources of strength and courage, thereby depriving this person of his or her autonomy and intrinsic virtues. This stance is present in certain attitudes and actions of pious compassion ${ }^{9}$. Compassion is understood here to be a situation of allowing oneself to be affected by 
the other person, not only through reason but also through feelings, and this is a way of understanding the other person, i.e. understanding how to act together with the other person rather than on the other person. Thus, this is the antithesis of the maxim that good professionals should not let themselves become emotionally involved, which is very frequently cited in medical settings. I think that good physicians should not let themselves become emotionally paralyzed, which is quite different.

\section{Responsibility}

This involves providing surety for our actions, i.e. guaranteeing that they are based on good reasons and that we remain interested in and committed towards their consequences. In other words, none of the values listed above can be attained on the basis of actions by physicians unless they understand the specific features of application of their knowledge in the material situations of the people who they care for, which of course includes the clinical and non-clinical consequences for the lives of these people. Unfortunately, our culture of specialties and the institutional fragmentation of medical work are frequently an obstacle preventing us from perceiving and implementing this broader responsibility. This leads us to assume that strict application of protocols and algorithms is our only task, as if this might exempt us from the intrinsic responsibility for care. In a manner that parallels what we see between compassion and autonomy, the aim here is not to subtract other people's own responsibility from them, or especially their freedom to make decisions, but to actively support people for whom we provide care within this process, which so often is a difficult task, especially when these individuals have been weakened through sickness or distress.

\section{THREE PURPOSES}

As we have seen above, virtues and values are always aimed towards real situations within day-to-day practice. Therefore, I think it is necessary to conclude by identifying the commitments that are inherent to the place that medical work and healthcare work in general occupy socially today, so that the above values and virtues can be brought a little closer to their horizon of application.
Clearly, the weight of each of purposes that are listed here will vary as a function of the different fields of professional activity. I will group them into three general types. Once again, there is no "esoteric" reason for establishing three types. They could be summarized into just one type, with a broad and radical idea of Care ${ }^{5}$ (with a capital letter). Or they could be unraveled to exhaustion, in the form of a checklist of tasks for a "universal professional". However, it seems to me that with these three types that I will now present, we can come close enough, within the limits of this text, to the meaning of Care within the day-to-day practice of physicians and healthcare teams in general.

\section{Receptiveness}

In all branches of medicine, but especially in those with the implication of dealing directly with people in healthcare clinics, it has to be recognized that healthcare work begins with the need to create effective contact with the other person. We have spoken about such encounters since the first lines of this text. Receptiveness means being actively ready to be challenged by the other person: hearing him/her out and sensing what he/she requires from us as care providers (not just at the time of the interpersonal interactions, but as collective workers and as the healthcare system too $)^{10}$. The importance of receptiveness is generally most clearly perceived at the places where people are welcomed to the healthcare unit: consultation offices, outpatient clinics, primary care units and hospitals (although this is unfortunately not always done satisfactorily). However, receptiveness can take place at any time during healthcare work. There may be a demand to be heard regarding a difficulty in the sexual sphere that emerges unexpectedly and indirectly during a routine gynecological examination; there may be a demand for an assessment of the "normality" of an adolescent's development in a situation in which this individual comes to the clinic with unclear complaints that are clinically unconnected; help may be sought by a victim of violence who comes to the clinic for treatment of chronic pain; an administrator may perceive that behind an apparently personal complaint from a user, a clinic may be presenting insufficiencies or inadequacies; or a policy-maker may read beyond the traditional health indicators to see a condition 
of vulnerability that calls for public responses.

\section{Dialogue}

In order to be receptive, and for the relationship with another person to materialize, the central tool of dialogue needs to be given its full value. Dialogue is synonymous with language in action, with words circulating between two or more subjects, thus allowing the horizons over which they discern the world to merge and leading to mutual comprehension (even if there is discordance regarding positions or conclusions $)^{11}$. For dialogue to take place, we need to be prepared to let the other person construct his own narratives about events, judgments and feelings that express his experience of health or disease and the projects of happiness that guide his seeking of care. This means that people for whom we provide care not only should answer questions that have been shown to be relevant through our technical and scientific expertise, but also should be able to guide us about which responses it will be relevant to obtain. Thus, it is fundamental to be open to the other person and, in listening to this person, to suspend all moralistic judgment. However, this does not mean abandoning the moral concerns that guide us; rather, we should avoid fitting what we hear and the decisions that we must take into premolded systems and judgments. Creation of spaces and mechanisms that are capable of effectively making other people's voices heard is indispensable for good medicine. There is a passage in "The death of Ivan Ilitch", the celebrated novel by Tolstoy, that illuminates what I am referring to with the expressive summarizing strength of art: "The doctor said: this and that indicate that you have this and that inside you; but if this is not confirmed by investigating this and that, we will have to suppose this and that in you, and therefore... etc. Only one question was of importance for Ivan Ilitch: did his condition present any danger? But the doctor did not give any importance to this inconvenient question" ${ }^{12}$.

\section{Response}

Medicine should always provide some form of response with regard to what has been actively or potentially demanded as a necessity of care. As we have seen, we must always respond in the best way, in line with people's projects of happiness, seeking solid knowledge and actions appropriate for each individual's and/or communities' reality and experiences, thus making ourselves co-responsible for combining technical and practical success ${ }^{5}$ within the care setting. Moreover, even without conclusive responses and even if the question was "inconvenient", the effective care provided for Ivan Ilitch involved an unanswered question that had not even been heard. As the English nurse, social worker, physician and writer Dame Cecily Saunders taught us: "suffering is only intolerable when nobody cares"13. We could add that health is also only constructed through care responses, thus agreeing with the theologian Leonardo Boff, who stated: "Care is the real support for creativity, freedom and intelligence. Within care, the fundamental ethos of human beings can be found" ${ }^{\prime \prime}$. Therefore, it is essential never to leave a demand for care unanswered. Even if the demand is hard for us to accept, or the path towards solutions is long or difficult, responses to care requirements need to be given. Care is always possible and necessary, and this is valid not only for healthcare professionals but also for administrators or policy-makers.

\section{ONE FINAL WORD}

We have come to the end of this brief essay in which we have revisited and, to some extent, reconstructed concepts and debates that, as shown here, have arisen over the centuries from different fields and authors. This should not be understood as a statement of a set of rules to be followed as a prescription, or proposals to be tested and accepted or refuted. Like everything in philosophy, even at this interface with medicine, this is above all an invitation to reflection and to share ways of seeing and dealing with human experience that might perhaps make us wiser and happier along our own paths. As Aristotle taught us, everything relating to human practices is condemned to be unpredictable, with opening of outcomes, and is destined to be unrepeatable ${ }^{1}$. This makes our judgments and decisions even more challenging yet fascinating, in medicine as in life. Therefore, why not accept the radical nature of this condition and exercise it with courage and humility, as the poet proposes to us? 


\section{Exercise}

Science, love, wisdom,

Everything lies too far, always

- immensely out of our reach.

- atoms are split,

tears are overcome,

abysses are bridged

- but soon we fall, faces down, eyes closed,

and one is a small secret

on a big secret.

We will still be sad for a long time,

although it's a noble sadness,

we, who the sun and the moon

meet every day

reflected on the mirror of silence,

in this long exercise of soul.*

$\left(\right.$ Cecília Meireles) ${ }^{14}$

\section{REFERENCES}

1. Aubenque P. A prudência em Aristóteles. São Paulo: Discurso Editorial; 2002.

2. Lalande A. Vocabulário técnico e crítico da filosofia. São Paulo: Martins Fontes; 1993.

3. Schraiber LB. No encontro da técnica com a ética: o exercício de julgar e decidir no cotidiano do trabalho em medicina. Interface (Botucatu). 1997;1(1):123-40. http://dx.doi. org/10.1590/S1414-32831997000200009.

4. Silva FL. Felicidade: dos filósofos pré-socráticos aos contemporâneos. São Paulo: Editora Claridade; 2007.

5. Ayres JRCM. Cuidado: trabalho e interação nas práticas de saúde. Rio de Janeiro: CEPESC, UERJ/IMS, ABRASCO; 2009. (Coleção Clássicos para Integralidade em Saúde). Disponível em: https://www.cepesc.org.br/wp-content/ uploads/2013/08/miolo-livro-ricardo.pdf.

6. Santos BS. A construção multicultural da igualdade e da diferença. Coimbra: Centro de Estudos Sociais; 1999. (Oficina do CES, publicação no. 135). Disponível em: http:// www.ces.uc.pt/publicacoes/oficina/135/135.pdf.

7. Habermas J. Verdade e justificação ensaios filosóficos. São Paulo: Edições Loyola; 2004.

*Freely translated by the author from the original Portuguese version.
8. Goldim JR. Compaixão, simpatia e empatia. 2006. Disponível em: http://www.bioetica.ufrgs.br/compaix.htm.

9. Caponi S. A lógica da compaixão. Transformação (Marília). 1999;21:91-117. Disponível em: http://www2.marilia.unesp. br/revistas/index.php/transformacao/article/view/803.

10. Teixeira RR. O acolhimento num serviço de saúde entendido como uma rede de conversações. In: Pinheiro R, Mattos RA, organizadores. Construção da integralidade: cotidiano, saberes e práticas em saúde. Rio de Janeiro: IMS-UERJ/ ABRASCO; 2003. p.89-111. Disponível em: http://www. corposem.org/rizoma/acolhiconversa.htm.

11. Gadamer HG. Verdade e método I: traços fundamentais de uma hermenêutica filosófica. 6a ed. Petrópolis: Vozes; 1997.

12. Tolstói L. A morte de Ivan Ilitch. 2a ed. São Paulo: Editora 34; 2009.

13. François A. Cuidar: um documentário sobre a medicina humanizada no Brasil. São Paulo: Ed. do Autor; 2006.

14. Meireles C. Obra poética. 3a ed. Rio de Janeiro: Nova Aguilar; 1987. 